\title{
Cost-effectiveness analysis of secukinumab versus other biologics and apremilast in the treatment of active Psoriatic arthritis: a Finnish perspective
}

\author{
Timo Purmonen ${ }^{1 *} \mathbb{D}$, Kari Puolakka², Devarshi Bhattacharyya ${ }^{3}$, Minal Jain ${ }^{3}$ and Janne Martikainen ${ }^{4}$
}

\begin{abstract}
Objective: To study cost-effectiveness of an interleukin (IL)-17A inhibitor secukinumab, with other biologics and apremilast in patients with Psoriatic arthritis (PsA) from payer perspective in Finland.

Methods: In this semi-Markov model, subcutaneous (SC) secukinumab was compared with SC treatments etanercept and its biosimilar, certolizumab pegol, adalimumab and its biosimilar, golimumab, ustekinumab, intravenous (IV) treatment infliximab, as well as oral non-biologic apremilast. Patients without prior exposure (naïve) to biologics and without moderate to severe psoriasis were considered for secukinumab 150 mg group. Secukinumab $300 \mathrm{mg}$ group included naive patients with moderate to severe psoriasis and all patients with prior biologic exposure. The PsA Response Criteria (PsARC) at 12-week was primary criteria for treatment response. Other clinical as well as cost related model inputs were derived from relevant clinical trials as well as Finnish publications. The key model outcomes were quality-adjusted life years and incremental cost-effectiveness ratio. An annual 3\% discount rate was applied to all future costs and benefits. Model input variations were assessed through sensitivity analyses and alternative scenario analyses.

Results: For a lifetime horizon (60 years), secukinumab $150 \mathrm{mg}$ dominated all branded SC biologics and apremilast with highest QALY of 8.01 and lowest lifetime cost of $€ 187,776$, while it was cost-effective against IV infliximab among biologic-naïve patients without moderate to severe psoriasis. Secukinumab $300 \mathrm{mg}$ was cost-effective against all branded SC biologics and apremilast and dominated IV infliximab among biologic-naïve patients with moderate to severe psoriasis, while it was cost-effective in biologic experienced patients. With the one-way sensitivity analysis, PSARC response, drug acquisition cost, and health assessment questionnaire score were the most important parameters affecting the outcomes. Across all treatment groups, patients on secukinumab were most likely to achieve highest net monetary benefit than other competitors in probabilistic sensitivity analysis. With alternative scenario analysis, results largely remained unchanged.
\end{abstract}

Conclusions: Secukinumab is a cost-effective treatment for PsA patients from a Finnish payer's perspective.

Keywords: Psoriatic arthritis, Cost-effectiveness, Biologics, Secukinumab, Incremental cost effectiveness ratio, Quality adjusted life years

*Correspondence: timo.purmonen@novartis.com

${ }^{1}$ Novartis Finland Oy, Espoo, Finland

Full list of author information is available at the end of the article 


\section{Introduction}

Psoriatic arthritis (PsA), a disease associated with psoriasis, is a chronic, multiform inflammation of joints, entheses and tendons but can also affect spine [1-4]. There are a lot of variations in the disease severity. Potentially, inflammation in PsA can lead to irreversible structural changes in joints and bones [5]. Incidence rates ranging from 10 to 23.1 per 100,000 person-years have been reported in local epidemiological studies [6, 7]. Painful joints and entheses limit patients' daily activities, which along with psoriatic skin involvement, causes substantial lowering of health-related quality of life [8]. In addition, PsA is associated with comorbidities, especially cardiovascular diseases, and poses significant economic burden over healthcare systems [9].

The European League against Rheumatism (EULAR) recommends the usage of conventional synthetic disease-modifying anti-rheumatic drugs (csDMARDs) as a first-line therapy for PsA patients. Patients with failure of or inadequate response to csDMARD should be considered for biologics like tumor necrosis factor Inhibitors (TNFi) and subsequently the interleukin inhibitors (IL 12/23 or IL 17 inhibitors) [10, 11]. The EULAR recommends the use of synthetic DMARD like apremilast in patients whom biologics are not appropriate. The Group for Research and Assessment of Psoriasis and Psoriatic arthritis (GRAPPA) recommends to start treatment with csDMARDs followed by TNFi and IL inhibitors, if patients have inadequate response to previous therapy. However, in case of enthesitis, dactylitis, or nail psoriasis, the GRAPPA recommends TNFi and IL inhibitors without a trial with csDMARDs $[12,13]$. In line with the EULAR and the GRAPPA guidelines, the Finnish current care guidelines also recommend starting the therapy with csDMARD (methotrexate) and switch to TNFi if such treatment is not tolerated or the response to treatment is inadequate. If TNFi are ineffective, switching to IL-17 inhibitors like secukinumab is recommended [14].

Secukinumab is a first-in-class, recombinant, highaffinity, fully human, monoclonal antibody that neutralizes IL-17A [4, 15]. In 2015, the European Medicines Agency approved secukinumab $300 \mathrm{mg}$ for the treatment of active PsA as subcutaneous injection for patients with concomitant moderate to severe psoriasis or inadequate response to TNFi and secukinumab $150 \mathrm{mg}$ for all other patients [16]. In multiple phase III placebo-controlled trials (FUTURE trials and their extensions), secukinumab showed rapid, significant, and sustained efficacy across various clinical domains with a favorable safety profile in biologic-naïve as well as in biologic-experienced patients (failure with up to three TNFi) [17-23]. In a recent network meta-analysis, secukinumab was found to be the most efficacious and safe treatment for PsA among all licensed IL-inhibitor biologics [24]. In addition, a matching-adjusted indirect comparison (MAIC) [25] established better efficacy of secukinumab against adalimumab. An ongoing head-to-head trial comparing secukinumab against adalimumab (EXCEED) [26] is aimed to confirm results obtained from the MAIC.

This study reports the results of a cost-effectiveness analysis of subcutaneous (SC) secukinumab versus currently licensed biologics, biosimilars (SC certolizumab pegol, etanercept and its biosimilar, adalimumab and its biosimilar, golimumab, ustekinumab and intravenous [IV] infliximab) and oral non biologic apremilast in Finland.

\section{Methods}

\section{Patient population and interventions}

The cost-effectiveness analysis was conducted in adult PsA patients of at least 18 years of age, with active disease in spite of treatment with NSAIDs, csDMARDs, and/or TNFi. The baseline patient characteristics were derived from the FUTURE 2 study [17], as shown in Additional file 1: Table S1. Patients were classified into three groups based on prior exposure and response to biologics and psoriasis severity as, (1) biologic-naïve (no prior exposure to biologics) without moderate to severe psoriasis, (2) biologic-naïve with moderate to severe psoriasis, and (3) biologic-experienced (having prior exposure to biologics). Biologic-naïve patients without moderate to severe psoriasis received $150 \mathrm{mg}$ of secukinumab, while biologic-naïve patients with moderate to severe psoriasis and biologic-experienced patients received secukinumab $300 \mathrm{mg}$. The secukinumab dosing regimen was based on the approved marketing authorization guidelines [16] and is reflective of the common prescription practice of rheumatologists in Finland. All patients are assumed to continue receiving concomitant standard of care $(\mathrm{SoC})$ treatments. Information related to treatment regimens like dosing and frequencies are provided in Additional file 1: Table S2.

\section{Model structure}

The model, as shown in Fig. 1, had a semi-Markov structure. This model is adapted from the recently published cost-effectiveness study of secukinumab in Canada [27]. Similar structure was used in the York model $[28,29]$ as well as other economic analyses of TNFi treatments for PsA [30-34]. This model also allowed assessment of the impact of adverse events, such as malignancy and tuberculosis, on mortality.

Treatment initiation defined the entry point for patients, while a 3-month duration was considered as induction period. At the end of the induction period, patients were evaluated for treatment response using 


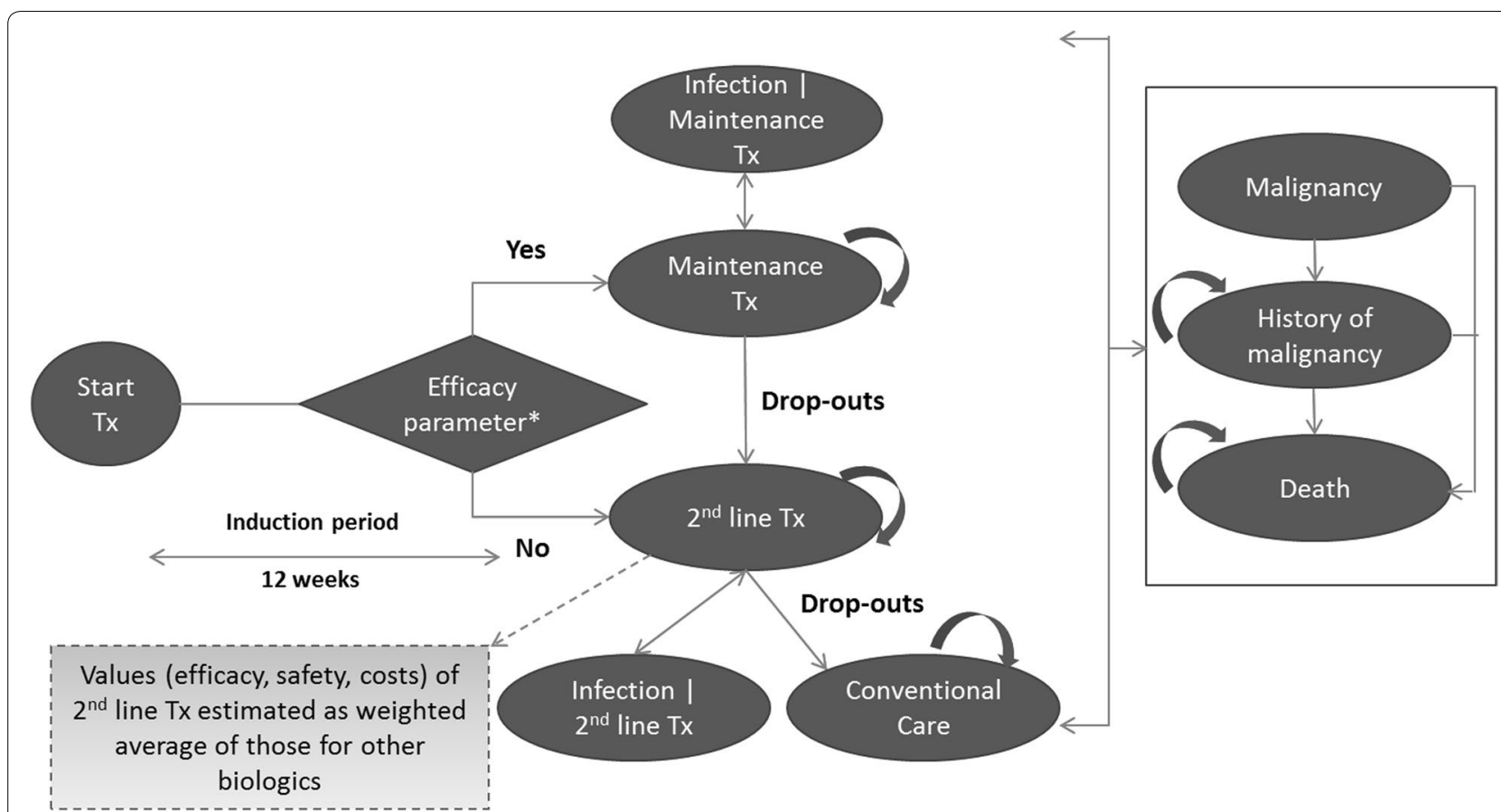

Fig. 1 Model structure. *The efficacy parameter depends on the criteria chosen—PSARC alone (for base case analysis), PASI, or a combination of PSARC and PASI (for alternative scenario analysis). Tx, treatment

the PsA response criteria (PsARC). The PsARC has been used extensively as a response criteria in similar analyses, including the York model, which allows comparability of this analysis with prior publications $[28,29,31-34]$. The PsARC as a treatment response criteria is also accepted by the National Institute of Health and Care Excellence (NICE) of the UK [35]. Based on treatment response, probabilities of withdrawal, serious infection including tuberculosis, malignancy, and death, patients transitioned to different health states (Fig. 1). Patients within the "Malignancy" state were assumed to be at a higher mortality risk for 5 years into that state.

Patients were able to withdraw from their initial biologic and transition to a subsequent/second line biologic as per preference of patients and/or physicians. As data on the effectiveness of subsequent biologics and treatment switches were limited, average values of efficacy, costs, treatment withdrawal rates, and adverse event rates were used for all biologics. Patients receiving subsequent biologics were assumed to continue on this treatment or move to the SoC if they dropped out.

\section{Model inputs \\ Clinical inputs}

The 3-month results for PsARC response, the Psoriasis Area and Severity Index (PASI) response, and change from baseline in the Health Assessment Questionnaire
(HAQ) were the main clinical inputs used in the model, as shown in Table 1. Due to the lack of head-to-head trials in the biologic-naïve population, comparative effectiveness data were obtained from a network metaanalysis (NMA) assessing PsARC and PASI outcomes [36], as shown in Additional file 1: Figures S1, S2.

Clinical efficacy in biologic-experienced patients is expected to be lower than that for biologic-naive patients [37]. Hence clinical efficacy data in biologic-experienced patients were calculated by applying adjustment rates to available clinical data that compared biologic-naïve to biologic-experienced patients $[17,38]$. Treatment withdrawals rates are provided in Additional file 1: Table S3. Wherever clinical data for a comparator were missing, average of relevant data from other comparators within similar population were used as a substitute.

\section{Cost and resource use}

Four types of costs were included: drug acquisition costs, disease-related costs, medical support costs, and adverse event costs, as shown in Table 2 and Additional file 1: Tables S4, S5. Wherever required, these costs were inflation adjusted with the latest available index and converted to Euro $(€)$.

The acquisition costs for all brand drugs were obtained from the Finnish medicinal products and prices database. Biosimilar prices for etanercept and adalimumab were 
Table 1 Clinical inputs at 3 months

\begin{tabular}{|c|c|c|c|c|c|c|c|c|c|}
\hline & SEC 150 & SEC 300 & CER P & ETN & ADA & INF & GOL & UST & APR \\
\hline \multicolumn{10}{|c|}{ PsARC response [36] (\% of patients) } \\
\hline Biologic Naïve ${ }^{a}$ & $59.82 \%$ & $51.18 \%$ & $73.61 \%$ & $70.91 \%$ & $62.84 \%$ & $78.65 \%$ & $79.96 \%$ & $73.61 \%$ & $73.61 \%$ \\
\hline Biologic experienced ${ }^{b}$ & N/A & $82.45 \%$ & $67.89 \%$ & $68.38 \%$ & $51.72 \%$ & $67.73 \%$ & $59.90 \%$ & $60.87 \%$ & $46.04 \%$ \\
\hline \multicolumn{10}{|c|}{ PASI response [36] (\% of patients) } \\
\hline PASI score & \multicolumn{9}{|c|}{ Biologic Naïve } \\
\hline $\mathrm{PASI}<50$ & $24.70 \%$ & $21.94 \%$ & $26.30 \%$ & $26.30 \%$ & $30.00 \%$ & $13.35 \%$ & $39.43 \%$ & $26.30 \%$ & $26.30 \%$ \\
\hline PASI 50-74 & $22.73 \%$ & $21.92 \%$ & $23.12 \%$ & $23.12 \%$ & $23.79 \%$ & $17.84 \%$ & $24.31 \%$ & $23.12 \%$ & $23.12 \%$ \\
\hline PASI 75-89 & $23.00 \%$ & $23.39 \%$ & $22.71 \%$ & $22.71 \%$ & $21.90 \%$ & $23.22 \%$ & $19.23 \%$ & $22.71 \%$ & $22.71 \%$ \\
\hline PASI 90-99 & $29.57 \%$ & $32.76 \%$ & $27.87 \%$ & $27.87 \%$ & $24.31 \%$ & $45.58 \%$ & $17.03 \%$ & $27.87 \%$ & $27.87 \%$ \\
\hline \multirow[t]{2}{*}{ PASI 100} & $0.00 \%$ & $0.00 \%$ & $0.00 \%$ & $0.00 \%$ & $0.00 \%$ & $0.00 \%$ & $0.00 \%$ & $0.00 \%$ & $0.00 \%$ \\
\hline & \multicolumn{9}{|c|}{ Biologic experienced ${ }^{d}$} \\
\hline PASI $<50$ & N/A & $19.63 \%$ & $74.10 \%$ & $74.48 \%$ & $58.98 \%$ & $48.84 \%$ & $63.39 \%$ & $58.00 \%$ & $80.40 \%$ \\
\hline PASI 50-74 & N/A & $16.87 \%$ & $11.80 \%$ & $11.72 \%$ & $12.47 \%$ & $8.83 \%$ & $12.86 \%$ & $12.31 \%$ & $10.11 \%$ \\
\hline PASI 75-89 & N/A & $23.01 \%$ & $8.91 \%$ & $8.76 \%$ & $13.96 \%$ & $14.30 \%$ & $12.64 \%$ & $14.17 \%$ & $6.47 \%$ \\
\hline PASI 90-99 & N/A & $40.49 \%$ & $5.20 \%$ & $5.04 \%$ & $14.60 \%$ & $28.03 \%$ & $10.82 \%$ & $15.52 \%$ & $3.01 \%$ \\
\hline PASI 100 & N/A & $0.00 \%$ & $0.00 \%$ & $0.00 \%$ & $0.00 \%$ & $0.00 \%$ & $0.00 \%$ & $0.00 \%$ & $0.00 \%$ \\
\hline \multicolumn{10}{|l|}{ Change in $\mathrm{HAQ}^{\text {e\# }}$} \\
\hline \multicolumn{10}{|l|}{ Biologic Naïve } \\
\hline Regardless of PsARC response & -0.4780 & -0.5780 & -0.2410 & -0.5259 & -0.3579 & -0.5578 & -0.3629 & -0.1988 & -0.2363 \\
\hline Given PsARC response & -0.5430 & -0.6880 & -0.3950 & -0.6400 & -0.4900 & -0.6600 & -0.4400 & -0.3950 & -0.3950 \\
\hline Given no PsARC response & -0.2310 & -0.2500 & 0.0000 & -0.2000 & -0.1400 & -0.2000 & -0.0600 & 0.0000 & 0.0000 \\
\hline \multicolumn{10}{|l|}{ Biologic experienced ${ }^{e}$} \\
\hline Regardless of PsARC response & N/A & -0.5360 & -0.2410 & -0.5259 & -0.3579 & -0.5578 & -0.3629 & -0.1988 & -0.2363 \\
\hline Given PsARC response & N/A & -0.5360 & -0.3950 & -0.6400 & -0.4900 & -0.6600 & -0.4400 & -0.3950 & -0.3950 \\
\hline Given no PsARC response & N/A & -0.3270 & 0.0000 & -0.2000 & -0.1400 & -0.2000 & -0.0600 & 0.0000 & 0.0000 \\
\hline
\end{tabular}

ADA, adalimumab; APR, apremilast, CER P, certolizumab pegol; ETN, etanercept; GOL, golimumab; INF, infliximab; PsARC, Psoriatic arthritis response criteria; SEC 150, secukinumab 150 mg; SEC 300, secukinumab 300 mg; UST, ustekinumab

a Biologic-naive data for certolizumab pegol and ustekinumab were not available and were assumed equivalent to be average of other biologics in the NMA. Trials for etanercept $50 \mathrm{mg}$ once weekly did not link into the network, thus data for etanercept $25 \mathrm{mg}$ twice weekly were used. Data for experienced population was lacking and was computed by applying a reduction to mixed population. Secukinumab: $0.43 \%$ reduction, other Tumor Necrosis Factor-alpha inhibitor (TNFi): $10.1 \%$

${ }^{b}$ Biologic-experienced data for ustekinumab were not available and were assumed equivalent to average of other biologics in the NMA. Trials for etanercept 50 mg once weekly did not link into the network, thus data for etanercept $25 \mathrm{mg}$ twice weekly were used

c Biologic-naive data for certolizumab pegol, etanercept, golimumab and ustekinumab were not available and were assumed equivalent to the average of other biologics in the network meta-analysis (NMA). Secukinumab $150 \mathrm{mg}$ was evaluated in biologic-naïve population without moderate to severe psoriasis and secukinumab $300 \mathrm{mg}$ was evaluated in biologic-naïve patients with moderate to severe psoriasis

d Data for experienced population was lacking and was computed by applying a reduction to mixed population. For Sec and other Tumor Necrosis Factor-alpha inhibitor (TNFi): PASI 50: $1.34 \%$ and $43.08 \%$ reduction, PASI 75: $6.84 \%$ and $40.64 \%$ reduction, PASI $90: 6.67 \%$ and $41.86 \%$

e Secukinumab 150 mg was evaluated in biologic-naïve population without moderate to severe psoriasis and secukinumab 300 mg was evaluated in biologic-naïve patients with moderate to severe psoriasis. For biologic-experienced patients, data were assumed equivalent to that of mixed population

\# Sources: Biologic experienced, regardless of PsARC response-SEC 150 and SEC 300 from FUTURE 2 trial; CER P set equal to placebo; ETN, ADA, INF, GOL, UST, and APR estimated from changes in HAQ with and without PSARC response and PsARC response probabilities; biologic experienced, given PsARC response-SEC 150, SEC 300 from FUTURE 2 trial; CER P, UST, and APR set equal to placebo; ETN, ADA, INF, and GOL from Cawson et al. [31]; biologic experienced, given no PsARC responseSEC 150 and SEC 300 from FUTURE 2 trial; CER P, UST, and APR set equal to placebo; ETN, ADA, INF, and GOL from Cawson et al. [31]; Biologic naïve, regardless of PsARC response-SEC 150, SEC 300, and placebo from FUTURE 2 trial; CER P, ETN, ADA, INF, GOL, UST, and APR set equal to biologic naïve or experienced, regardless of PSARC response; biologic naïve, given PSARC response-SEC 150, SEC 300 from FUTURE 2 trial; CER P, ETN, ADA, INF, GOL, UST, and APR set equal to biologic naïve or experienced, given PsARC response; biologic naïve, given no PsARC response-SEC 150 and SEC 300 from FUTURE 2 trial; CER P, ETN, ADA, INF, GOL, UST, APR set equal to biologic naïve or experienced, given no PsARC response

considered 30\% less than that for the brand price. Due to unavailability of Finnish PsA related costs, this category of costs were retrieved from the published York model in PsA (Table 2) [28]. A linear regression method based on the change from baseline in HAQ scores was employed to obtain the arthritis-related costs. The psoriasis-related costs were based on PASI response, taking into account both uncontrolled $(\mathrm{PASI}<75)$ and controlled $(\mathrm{PASI} \geq 75)$ disease states. Costs related to medical support and adverse events were based on national healthcare unit costs and were confirmed by expert advice (Additional file 1: Tables S4, S5). 
Table 2 Costs inputs

\begin{tabular}{|c|c|c|}
\hline Drug/input & Cost $(€)$ & Unit \\
\hline \multicolumn{3}{|l|}{ Drug acquisition costs ${ }^{a}$} \\
\hline SEC $150 \mathrm{mg}$ & 584.43 & Per dose \\
\hline SEC 300 mg & 1168.86 & Per dose \\
\hline CER P $200 \mathrm{mg}$ & 483.07 & Per prefilled syringe \\
\hline ETN 50 mg & 260.04 & Per prefilled syringe \\
\hline ADA $40 \mathrm{mg}$ & 527.41 & Per prefilled syringe \\
\hline INF 100 mg & 436.06 & Per vial \\
\hline GOL 50 mg & 1086.93 & Per prefilled syringe \\
\hline UST 45/90 mg & 3124.96 & Per prefilled syringe \\
\hline APR $10-30 \mathrm{mg}$ & 418.52 & Per 14 day pack \\
\hline APR $30 \mathrm{mg}$ & 14.93 & Per tablet \\
\hline ETN biosimilar 50 mg & 182.02 & Per prefilled syringe \\
\hline ADA biosimilar 40 mg & 369.19 & Per prefilled syringe \\
\hline MTX $7.5 \mathrm{mg}$ & 0.51 & Per dose \\
\hline \multicolumn{3}{|l|}{ Disease-related costs } \\
\hline Intercept & 297.89 & Per 3 months \\
\hline Cost per HAQ change & 131.61 & $\begin{array}{l}\text { Per 1-unit change per } \\
\text { 3-months }\end{array}$ \\
\hline \multicolumn{3}{|l|}{ Health states } \\
\hline Uncontrolled psoriasis (PASI < 75) & 253.14 & Per 3 months \\
\hline Controlled psoriasis (PASI $\geq 75$ ) & 20.46 & Per 3 months \\
\hline
\end{tabular}

ADA, adalimumab; APR, apremilast; CER P, certolizumab pegol; ETN, etanercept; $\mathrm{GOL}$, golimumab; $\mathrm{HAQ}$, Health Assessment Questionnaire; INF, infliximab; LEF, leflunomide; MTX, methotrexate; PASI, Psoriasis Area Severity Index; SEC, secukinumab; SUL, sulfasalazine; UST, ustekinumab

Source: Costs from the York model (Rodgers et al., [28]) who extracted costs from the following sources. Cost for a 1-point change in HAQ obtained from Kobelt et al. [49]. Cost for uncontrolled psoriasis obtained from Department of Health [50]. Cost for controlled psoriasis obtained from Hartman et al. [51]

a Finnish medicinal products and prices database [accessed on-line 2.1.2018]. All prices exclude value added tax. Retail price for SC products, and wholesale price for IV products is applied according to local guidelines. Infliximab price is weighed with market share. A cost of $€ 382$ (2016 value) is added for each IV administration [48] Biosimilar pricing for etanercept and adalimumab assumed to be $30 \%$ less than brand; they were not available in the market at the time of analyses, and thus only used for sensitivity analysis obtain productivity loss due to unemployment for each category (Additional file 1: Table S5).

\section{Other inputs}

In the base case analysis, utility values from the FUTURE 2 trial [17] were used for each cycle, which were calculated by converting EQ-5D scores with Dolan [40] algorithm using a representative UK population. Utility values for scenario analysis were taken from the York model, [28] which were calculated by using HAQ and PASI scores and applying linear regression method. The values are shown in Additional file 1: Table S6. Three mortality risks were included in the analysis as shown in Additional file 1: Table S7. Finnish age-specific life tables were used to take into account the all-cause mortality. The disease-specific mortality risk was based on risk values used in the York model [28]. The adverse eventrelated mortality risk is based on the evidence showing similar mortality risk for PsA patients to that of the general population [41].

\section{Base case analysis}

The base case analysis compared cost-effectiveness of secukinumab $150 \mathrm{mg}$ and $300 \mathrm{mg}$ with that of licensed biologics, their biosimilars, and apremilast from a Finnish payer's perspective. Using quality-adjusted life years (QALYs) as the primary effectiveness outcome, secukinumab's dominance over other comparators was assessed. Dominance was defined as having higher QALY at lower cost over a comparator. In case secukinumab was non-dominant, the incremental cost-effectiveness ratio (ICER) was reported. A commonly referred willingness-to-pay (WTP) threshold of $€ 30,000 / Q A L Y$ was used for assessing the cost-effectiveness, as there is no mandated WTP threshold in Finland. Annual discount rates of $3 \%$ were applied for both future costs and outcomes. The analysis was done for a lifetime horizon of 60 years.

\section{Sensitivity analyses}

Three sensitivity analyses assessed the impact of variations of input parameters on the base case results. In one-way deterministic analysis, input parameters likely to have the greatest impact on the results (e.g., PsARC response rate, HAQ change, and utility weights) were varied one at a time.

The scenario analyses allowed changing model structures and assumptions to ascertain their impact on base case results. Some of these scenarios included time horizons of 5 and 10 years, discount rates of $0 \%$ and $5 \%$, alternative utility values, addition of indirect costs, inclusion of disutilities, and HAQ score retaining after treatment withdrawal. 
In probabilistic sensitivity analysis, certain distributions were assigned for input parameters to assess the impact of sampling uncertainty. Input parameters like response rate, costs, and utility weights were varied in this analysis. The net monetary benefit (NMB) statistics was used for this analysis, as it allows simultaneous comparisons of multiple comparators [42]. NMB represents monetary value of a comparator at a defined WTP.

\section{Results}

\section{Base case results}

The QALYs, cost, and ICER related results for base case are provided in Table 3. For biologic-naïve patients without moderate to severe psoriasis, secukinumab $150 \mathrm{mg}$ dominated all SC administered biologics, biosimilars, as well as the oral apremilast by achieving highest QALY $(8.01)$ at lowest life-time cost $(€ 187,776)$. The IV administered infliximab had slightly higher QALY $(+0.06)$, but at an ICER of €680,427/QALY gained vs secukinumab. Hence infliximab was not considered as a cost-effective option compared with secukinumab $150 \mathrm{mg}$.

In biologic-naïve patients with moderate to severe psoriasis, secukinumab $300 \mathrm{mg}$ achieved the highest QALY (7.78) against all biologics, biosimilars, and oral apremilast at the life-time cost of $€ 231,477$. Based on the WTP of $€ 30,000 / Q A L Y$, secukinumab $300 \mathrm{mg}$ was cost-effective against all SC branded biologics but not against the SC biosimilars of etanercept and adalimumab. Secukinumab $300 \mathrm{mg}$ was cost-effective against oral apremilast, while it dominated the IV infliximab with higher QALYs and lower costs.
Biologic-experienced patients on secukinumab $300 \mathrm{mg}$ achieved highest QALY (8.75) against all biologics, biosimilars, and oral apremilast at the life-time cost of $€ 256,019$. Secukinumab was cost-effective against all branded biologics and oral apremilast. When compared to etanercept and adalimumab biosimilars, the ICER was above the $€ 30,000$ WTP threshold.

Multiple comparison across comparators was conducted through cost-effectiveness frontier, as seen in Fig. 2. In the biologic naïve population without moderate to severe psoriasis, secukinumab $150 \mathrm{mg}$, etanercept biosimilar, adalimumab biosimilar, and infliximab had the highest cost-effectiveness. In biologic naïve patients with moderate to severe psoriasis, etanercept biosimilar and secukinumab $300 \mathrm{mg}$ were the most costeffective options. Lastly, in biologic experienced population etanercept biosimilar, adalimumab biosimilar, and secukinumab $300 \mathrm{mg}$ were the most cost-effective options. Overall, secukinumab was the only branded biologic to be cost-effective in multiple comparison across all patient groups.

\section{Sensitivity analyses}

In the one-way sensitivity analysis, across all patient groups, PsARC response at 3-month, drug acquisition cost, and HAQ without PsARC response were the most important input parameters that affected the expected net monetary benefits. Detailed results are shown in tornado diagrams in Additional file 1: Figures S3-S5.

Complete description of alternative inputs for different scenarios and their impact on the base case results

Table 3 Costs, QALYs and ICER values for all analyzed populations

\begin{tabular}{|c|c|c|c|c|c|c|c|c|c|c|}
\hline \multirow[t]{2}{*}{ Incremental } & \multicolumn{8}{|l|}{ SC } & \multirow{2}{*}{$\begin{array}{l}\text { IV } \\
\text { INF }\end{array}$} & \multirow{2}{*}{$\begin{array}{l}\text { Oral } \\
\text { APR }\end{array}$} \\
\hline & SEC & ETN & ETN BS & ADA & ADA BS & CER P & GOL & UST & & \\
\hline \multicolumn{11}{|c|}{ SEC 150 mg versus comparators in Biologic Naïve population without moderate to severe psoriasis) } \\
\hline Total cost $(€)$ & 187,776 & 208,375 & 186,581 & 207,568 & 186,543 & 204,899 & 197,566 & 214,749 & 230,650 & 192,319 \\
\hline QALYS & 8.01 & 7.67 & 7.67 & 7.47 & 7.47 & 7.34 & 7.15 & 7.54 & 8.07 & 7.13 \\
\hline ICER (€/QALY) & - & Dominates & 3514 & Dominates & 2283 & Dominates & Dominates & Dominates & $680,427^{a}$ & Dominates \\
\hline \multicolumn{11}{|c|}{ SEC 300 mg versus comparators in Naïve PsA with moderate to severe psoriasis population } \\
\hline Total cost $(€)$ & 231,477 & 214,225 & 192,431 & 213,555 & 192,530 & 210,480 & 203,855 & 220,313 & 235,354 & 198,422 \\
\hline QALYS & 7.78 & 7.12 & 7.12 & 6.9 & 6.9 & 6.78 & 6.57 & 6.98 & 7.54 & 6.57 \\
\hline ICER (€/QALY) & - & 25,872 & 49,365 & 20,342 & 37,251 & 20,955 & 22,819 & 13,941 & Dominates & 27,233 \\
\hline \multicolumn{11}{|c|}{ SEC 300 mg versus comparators in experienced population } \\
\hline Total cost $(€)$ & $256,019 €$ & 215,772 & 194,424 & 210,940 & 191,975 & 211,230 & 201,556 & 217,194 & 231,440 & 196,293 \\
\hline QALYS & 8.75 & 7.35 & 7.35 & 7.05 & 7.05 & 7.00 & 6.75 & 7.12 & 7.61 & 6.68 \\
\hline ICER (€/QALY) & - & 28,742 & 40,546 & 26,609 & 34,959 & 25,623 & 27,293 & 23,832 & 21,631 & 28,939 \\
\hline
\end{tabular}

ADA, adalimumab; APR, apremilast; BS, biosimilar; CER P, certolizumab pegol; ETN, etanercept; GOL, golimumab; INF, infliximab; IV, Intra Venous; PsARC, Psoriatic arthritis response criteria; QALY, quality-adjusted life-year; SEC 150, secukinumab 150 mg; SEC 300, secukinumab 300 mg; SC, subcutaneous; SoC, standard of care; UST, ustekinumab

a The ICER of Sec $150 \mathrm{mg}$ vs. INF 

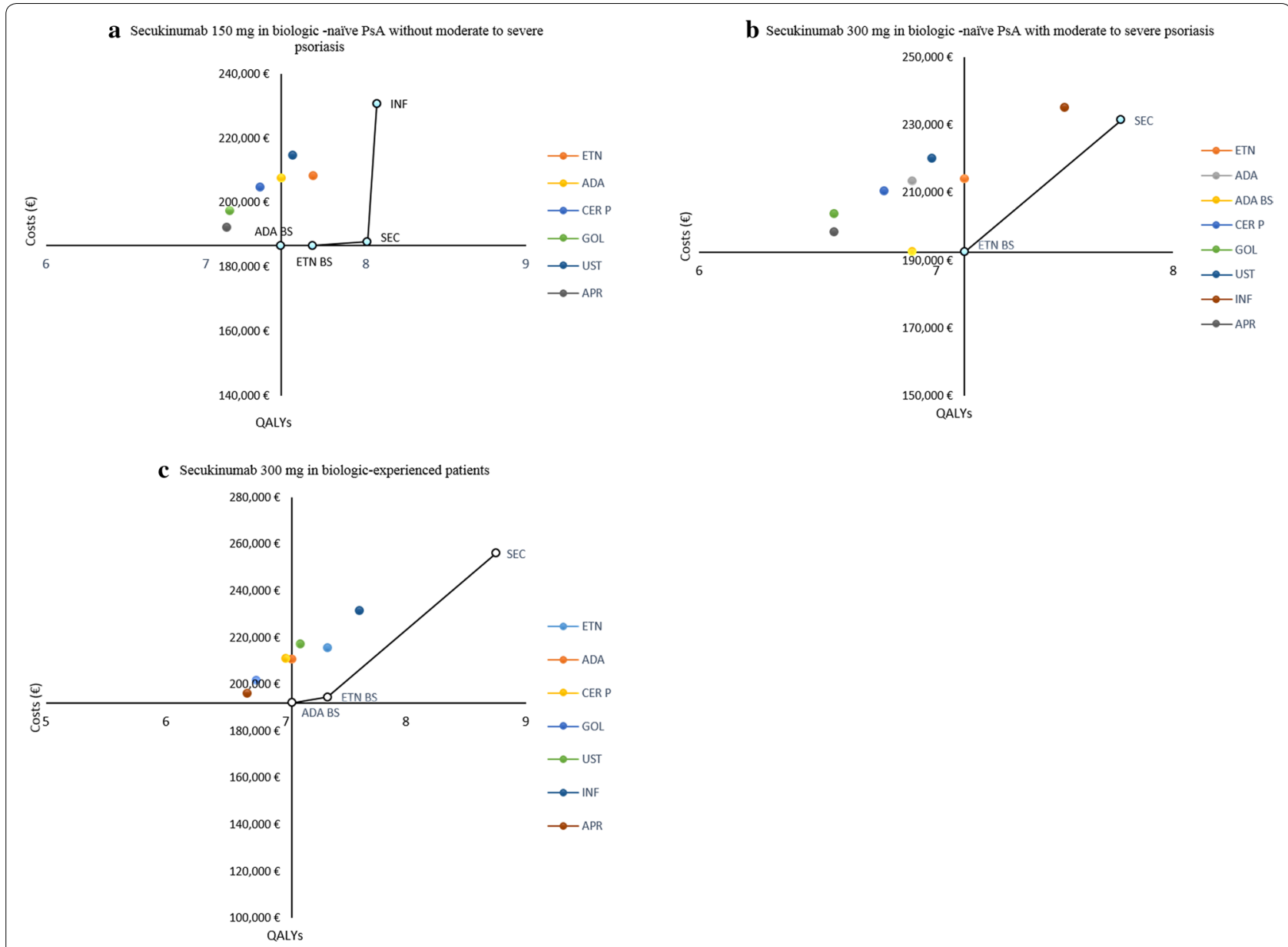

Fig. 2 Cost effective frontier: a secukinumab 150 mg, b secukinumab 300 mg, c secukinumab 300 mg. ADA, adalimumab; APR, apremilast; BS, biosimilar; CER P, certolizumab pegol; ETN, etanercept; GOL, golimumab; INF, infliximab; PSA, Psoriatic arthritis; QALYS, quality adjusted life years; SEC, secukinumab; UST, ustekinumab

are shown in Additional file 1: Table S8. In majority of alternative scenarios, the results were similar to that from the base case, suggesting the robustness of our analysis.

In the probabilistic sensitivity analysis, patients on secukinumab were most likely to achieve highest QALY compared to all other comparators. Probability of achieving highest $\mathrm{NMB}$ was more than $70 \%$ in biologic-naïve patients on secukinumab $150 \mathrm{mg}$ at WTP of $€ 30,000$ (Additional file 1: Table S9). In patients receiving secukinumab $300 \mathrm{mg}$, irrespective of prior biologic experience, probability of achieving highest NMB was over $83 \%$ at WTP of $€ 30,000$ (Additional file 1: Table S9). The costeffectiveness acceptability curves indicated that secukinumab had the highest probability of being cost-effective vs other comparators at the WTP threshold ranging from $€ 20,000$ to $€ 100,000$ across the three patient populations (Fig. 3). The details of the probabilistic sensitivity analysis are presented in Additional file 1: Table S9.

\section{Discussion}

In this analysis, secukinumab proved to be either the dominant or cost-effective treatment option against all biologics and the oral apremilast among PsA patients. These results hold true in all analyzed patient populations, irrespective of their prior exposure to biologics.

With highest QALYs and lowest cost, secukinumab $150 \mathrm{mg}$ provides the best economic value amongst biologic-naive patients without moderate to severe psoriasis. Even with slightly higher QALYs $(0.06)$, the choice of infliximab is still not justified due to its significantly higher costs $(>€ 42,000)$ than secukinumab. Considering the ease of administration and lower costs, SC secukinumab may be more desirable by both patients and physicians over the IV infliximab $[43,44]$.

Secukinumab $300 \mathrm{mg}$ was also cost-effective in both biologic-naïve (with moderate to severe psoriasis) and experienced patients compared with all branded SC biologics and oral apremilast at WTP $€ 30,000 /$ QALY, 

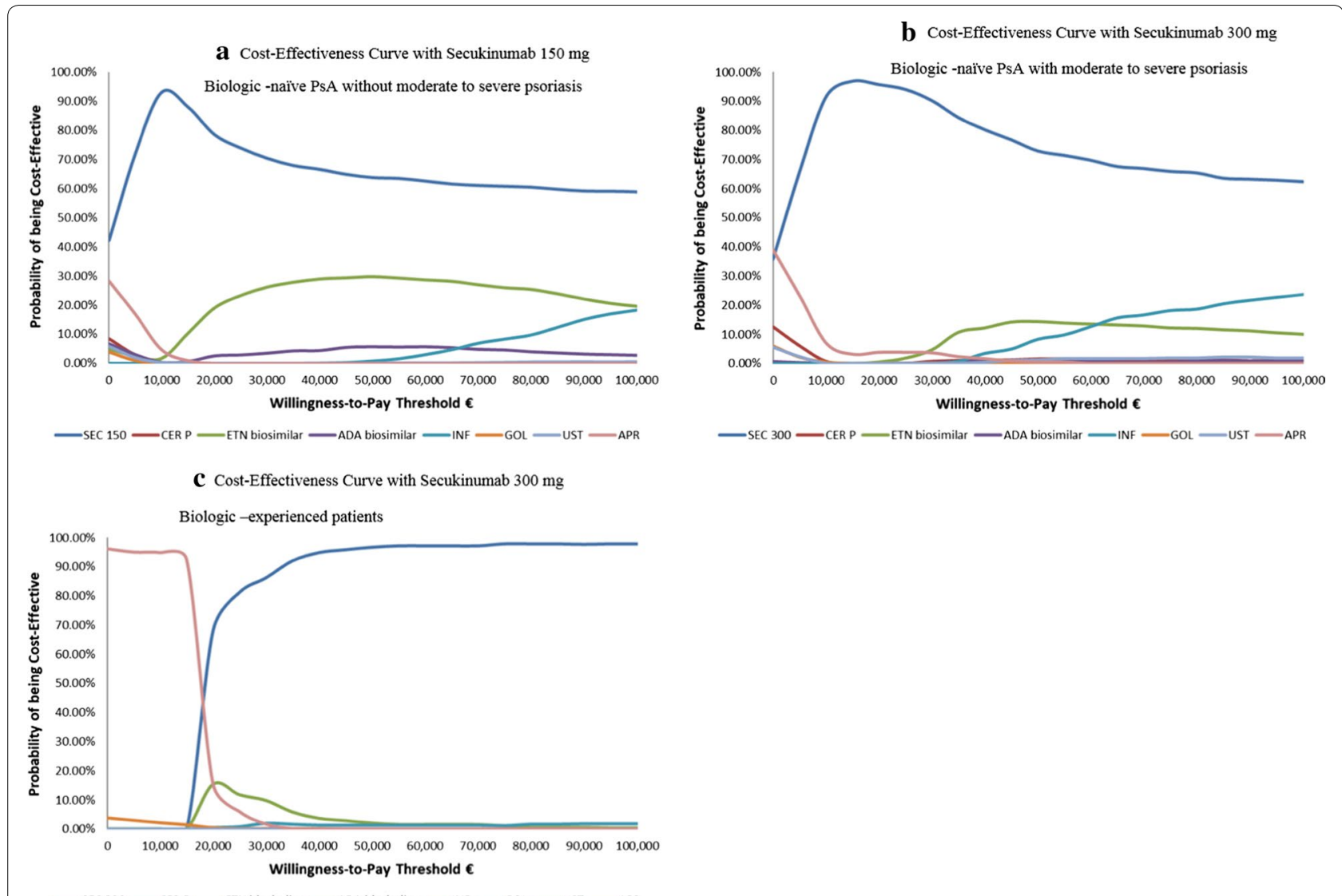

Fig. 3 Probability of achieving highest NMB: Cost-effectiveness Acceptability Curve with a secukinumab 150 mg, b secukinumab 300 mg, c secukinumab 300 mg. ADA, adalimumab; APR, apremilast; CER P, certolizumab pegol; ETN, etanercept; GOL, golimumab; INF, infliximab; SEC, secukinumab; UST, ustekinumab

while it dominated the IV infliximab in these subpopulations with lower costs and higher QALYs. Secukinumab $300 \mathrm{mg}$ achieved higher QALYs than biosimilars of adalimumab (biologic-naïve: +0.88 ; biologic experienced: +1.70 ) and etanercept (biologic-naïve: +0.66 ; biologic experienced: +1.40$)$. However, ICER for secukinumab compared to these biosimilars were above $€ 30,000 / \mathrm{QALY}$ gained.

This being a first comprehensive economic analysis of secukinumab against multiple treatment choices in Finland, will help both payers and physicians in their decision making. So far, most of such analyses have focused on the UK perspective and have largely compared etanercept to various biologics [28-34]. This analysis compares secukinumab, a newer biologic with a new mode of action, to the current standard biologic TNFi, TNFi biosimilars, as well as oral apremilast.

The strength of this analysis can be attributed to various factors. The clinical inputs in the model were taken from an NMA, consisting of 6021 patients in 20 RCTs. Patients in this NMA were a mix of those with and without prior biologic exposure, which makes clinical inputs in this model reliable. Inclusion of costs like hospitalization costs and diagnosis costs, in addition to drug acquisition and adverse event costs, allows comprehensive representation of direct economic burden of PsA. The model results are robustly tested through both probabilistic and deterministic sensitivity analyses, while the model structure and methodology are similar to those used in a model for Canadian healthcare system [27].

This model-based analysis naturally has some limitations. One limitation of the analysis lies in the use of efficacy data from the NMA that used short-term study period of 12-16 weeks to project life-time efficacy. However, use of short term data may have underestimated the long-term efficacy of secukinumab over its comparators. For example, in one of the MAIC analysis, long term efficacy of adalimumab [25, 45], etanercept [46], and infliximab [47] were compared to that of secukinumab. In these studies covering a period of more than 3 years, secukinumab maintained its significantly higher efficacy over the TNFi. Another limitation is the assumption that 
efficacy for the biologics with missing data was equal to the average of other biologics. Finally, indirect costs were not included in the base case analysis as the model is from a payer's perspective. Nevertheless, inclusion of indirect costs did not affect the model results, as explored in the alternative scenario analysis.

\section{Conclusion}

Patients on secukinumab achieved highest gains in the quality adjusted life-years against all comparators regardless of secukinumab dose, severity of concomitant psoriasis, or prior exposure to biologics. Secukinumab was either cost-saving or cost-effective when compared with the currently used alternative treatment options for the treatment of active Psoriatic arthritis from a payer's perspective in Finland.

\section{Additional file}

Additional file 1. Sensitivity analyses and model input parameters

\section{Authors' contributions}

All authors were involved in the economic analysis and approved methodology and input data. The authors contributed to writing and review of the manuscript. All authors read and approved the final manuscript.

\section{Author details}

${ }^{1}$ Novartis Finland Oy, Espoo, Finland. ${ }^{2}$ South Karelia Social and Health Care District, Lappeenranta, Finland. ${ }^{3}$ Novartis Product Life Cycle Services-NBS, Novartis Healthcare Private Limited, Hyderabad, India. ${ }^{4}$ School of Pharmacy, University of Eastern Finland, Kuopio, Finland.

\section{Acknowledgements}

The authors acknowledge Dr. Ketan Makawana from Novartis for his role in providing editorial assistant for the publication.

\section{Competing interests}

Drs. Timo Purmonen, Devarshi Bhattacharyya, and Minal Jain were salaried employees of Novartis at the time of the research. Dr. Kari Puolakka reports personal fees and non-financial support from Abbvie and Pfizer and personal fees from Bristol-Myers Squibb, Lilly, MSD, Novartis, Roche, Sandoz, and UCB outside the submitted work. Dr. Janne Martikainen reports personal fees from Esior Oy outside the submitted work.

\section{Availability of data and materials}

The corresponding author can be contacted regarding reasonable requests for data and other relevant material.

\section{Consent for publication}

All authors consent to the publication of the manuscript.

\section{Ethics approval and consent to participate}

No patients/participants were involved in the research and no ethics approval was required.

\section{Funding}

This study was funded by Novartis Pharma AG, Basel, Switzerland.

\section{Publisher's Note}

Springer Nature remains neutral with regard to jurisdictional claims in published maps and institutional affiliations.
Received: 13 August 2018 Accepted: 8 November 2018

Published online: 16 November 2018

\section{References}

1. Taylor WJ, Mease PJ, Adebajo A, et al. Effect of Psoriatic arthritis according to the affected categories of the international classification of functioning, disability and health. J Rheumatol. 2010;37(9):1885-91.

2. Gladman DD, Antoni C, Mease P, et al. Psoriatic arthritis: epidemiology, clinical features, course, and outcome. Ann Rheum Dis. 2005;Suppl 2:ii14-7.

3. Mease PJ, Armstrong AW. Managing patients with psoriatic disease: the diagnosis and pharmacologic treatment of Psoriatic arthritis in patients with psoriasis. Drugs. 2014;74(4):423-41.

4. Kang EJ, Kavanaugh A. Psoriatic arthritis: latest treatments and their place in therapy. Ther Adv Chronic Dis. 2015;6(4):194-203.

5. Schett G, Lories RJ, D’Agostino MA, et al. Enthesitis: from pathophysiology to treatment. Nat Rev Rheumatol. 2017;13(12):731-41.

6. Savolainen E, Kaipiainen-Seppanen $\mathrm{O}$, Kroger $\mathrm{L}$, et al. Total incidence and distribution of inflammatory joint diseases in a defined population: results from the Kuopio 2000 arthritis survey. J Rheumatol. 2003;30(11):2460-8

7. Rantalaiho V, Kautiainen $\mathrm{H}$, Virta L, et al. FRI0560 the increase in the nationwide incidence of inflammatory rheumatic diseases in finland during this millennium. Ann Rheum Dis. 2016;75(Suppl 2):643-4.

8. Kavanaugh A, Helliwell P, Ritchlin CT. Psoriatic arthritis and burden of disease: patient perspectives from the population-based multinational assessment of Psoriasis and Psoriatic arthritis (MAPP) survey. Rheumatol Ther. 2016;3(1):91-102.

9. Lee S, Mendelsohn A, Sarnes E. The burden of Psoriatic arthritis: a literature review from a global health systems perspective. Pharm Ther. 2010;35(12):680-9.

10. Gossec L, Smolen JS, Gaujoux-Viala C, et al. European league against rheumatism recommendations for the management of Psoriatic arthritis with pharmacological therapies. Ann Rheum Dis. 2012;71(1):4-12.

11. Gossec L, Smolen JS, Ramiro S, et al. European league against Rheumatism (EULAR) recommendations for the management of Psoriatic arthritis with pharmacological therapies: 2015 update. Ann Rheum Dis. 2016;75(3):499-510.

12. Coates LC, Kavanaugh A, Mease PJ, et al. Group for research and assessment of Psoriasis and Psoriatic arthritis 2015 treatment recommendations for Psoriatic arthritis. Arthritis Rheumatol. 2016;68(5):1060-71.

13. Ritchlin CT, Kavanaugh A, Gladman DD, et al. Treatment recommendations for Psoriatic arthritis. Ann Rheum Dis. 2009;68(9):1387-94.

14. Psoriasis (skin and joint): Current Care Guidelines. Working group set up by the Finnish Medical Society Duodecim and the Finnish Dermatological Society:: The Finnish Medical Society Duodecim; 2017. http://www. kaypahoito.fi.

15. Boyd T, Kavanaugh A. Interleukin-17 inhibition in Psoriatic arthritis. Clin Exp Rheumatol. 2015;33(5 Suppl 93):S119-23.

16. EMA. Cosentyx: EPAR Product Information. 2016 (Cosentyx-EMEA/H/C/003729-T/0036).

17. Mclnnes IB, Mease PJ, Kirkham B, et al. Secukinumab, a human antiinterleukin-17A monoclonal antibody, in patients with Psoriatic arthritis (FUTURE 2): a randomised, double-blind, placebo-controlled, phase 3 trial. Lancet. 2015;386(9999):1137-46.

18. Kavanaugh A, Mease PJ, Reimold AM, et al. Secukinumab for longterm treatment of Psoriatic arthritis: 2-year follow-up from a phase 3, randomized, double-blind, placebo-controlled study. Arthritis Care Res. 2016:69(3):347-55

19. Mease PJ, Kavanaugh A, Reimold A, et al. Secukinumab provides sustained improvements in the signs and symptoms of active Psoriatic arthritis through 3 years: efficacy and safety results from a phase 3 trial [abstract]. Arthritis Rheumatol. 2016;68(10).

20. Mease PJ, Mclnnes IB, Kirkham B, et al. Secukinumab inhibition of interleukin-17A in patients with Psoriatic arthritis. N Engl J Med. 2015:373(14):1329-39.

21. Kavanaugh A, McInnes IB, Mease PJ, et al. Efficacy of subcutaneous Secukinumab in patients with active psoriatic arthritis stratified by prior 
tumor necrosis factor inhibitor use: results from the randomized placebocontrolled FUTURE 2 study. J Rheumatol. 2016;43(9):1713-7.

22. Mease P, Kavanaugh A, Reimold A, et al. Secukinumab provides sustained improvements in the signs and symptoms of active Psoriatic arthritis: 3-year efficacy and safety results from phase 3 FUTURE 1 trial. Ann Rheum Dis. 2017;76(Suppl 2):952-3.

23. Gottlieb A B DEM, Pellet P, Kajekar R, Pricop L, editor. Secukinumab provides sustained improvement in signs and symptoms of patients with active Psoriatic arthritis up to 3 years: Data from FUTURE 1 and FUTURE 2 studies. EADV. 2017. https://eadvgeneva2017.org/e-congress/onlin e-resources/. Accessed 14 Mar 2018.

24. Wu D, Yue J, Tam LS. Efficacy and safety of biologics targeting interleukin-6, $-12 / 23$ and -17 pathways for peripheral Psoriatic arthritis: a network meta-analysis. Rheumatology (Oxford). 2018;57(3):563-71.

25. Nash P, McInnes I, Mease P, et al. Secukinumab for the treatment of Psoriatic Arthritis: comparative effectiveness versus adalimumab using a matching-adjusted indirect comparison. Arthritis Rheumatol. 2016;68(suppl 10):99.

26. Efficacy of Secukinumab compared to adalimumab in patients with Psoriatic arthritis (EXCEED 1) [Internet]. 2017. https://clinicaltrials.gov/ct2/ show/NCT02745080. Accessed 12 Dec 2017.

27. Goeree R, Chiva-Razavi S, Gunda P, et al. Cost-effectiveness analysis of Secukinumab for the treatment of active Psoriatic arthritis: a Canadian perspective. J Med Econ. 2018;21(2):163-73.

28. Rodgers M, Epstein D, Bojke L, et al. Etanercept, infliximab and adalimumab for the treatment of Psoriatic arthritis: a systematic review and economic evaluation. Health Technol Assess. 2011;15(10):1-329.

29. Woolacott N, Bravo Vergel Y, Hawkins N, et al. Etanercept and infliximab for the treatment of Psoriatic arthritis: a systematic review and economic evaluation. Health Technol Assess. 2006;10(31):1-239.

30. Bravo Vergel Y, Hawkins NS, Claxton K, et al. The cost-effectiveness of etanercept and infliximab for the treatment of patients with Psoriatic arthritis. Rheumatology (Oxford). 2007:46(11):1729-35.

31. Cawson MR, Mitchell SA, Knight C, et al. Systematic review, network meta-analysis and economic evaluation of biological therapy for the management of active Psoriatic arthritis. BMC Musculoskelet Disord. 2014;15:26

32. Bojke L, Epstein D, Craig D, et al. Modelling the cost-effectiveness of biologic treatments for Psoriatic arthritis. Rheumatology (Oxford). 2011;Suppl 4:iv39-47.

33. Cummins E, Asseburg C, Punekar YS, et al. Cost-effectiveness of infliximab for the treatment of active and progressive Psoriatic arthritis. Value Health. 2011;14(1):15-23.

34. Cummins E, Asseburg C, Prasad M, et al. Cost effectiveness of golimumab for the treatment of active Psoriatic arthritis. Eur J Health Econ. 2012;13(6):801-9.

35. NICE Multiple Technology Appraisal—Certolizumab pegol and Secukinumab for treating active Psoriatic arthritis following inadequate response to disease modifying anti-rheumatic drugs [Internet]. 2016. https://www.nice.org.uk/guidance/ta445/documents/html-content-3. Accessed 31 Aug 2017.
36. McInnes I, Nash P, Ritchlin C, et al. Secukinumab for the treatment of Psoriatic arthritis: comparative effectiveness results versus licensed biologics and Apremilast from a network meta-analysis. Ann Rheum Dis. 2016;75(2):348.

37. Reddy SM, Crean S, Martin AL, et al. Real-world effectiveness of anti-TNF switching in Psoriatic arthritis: a systematic review of the literature. Clin Rheumatol. 2016;35(12):2955-66.

38. Gladman DD, Sampalis JS, Illouz O, et al. Responses to adalimumab in patients with active Psoriatic arthritis who have not adequately responded to prior therapy: effectiveness and safety results from an open-label study. J Rheumatol. 2010;37(9):1898-906.

39. Conaghan $P G$, Alten $R$, Strand $V$, et al. The relationship between physical functioning and work for people with Psoriatic arthritis: results from a large real-world study in 16 countries. Arthritis Rheum. 2016;68(Suppl 10): 111

40. Dolan P. Modeling valuations for EuroQol health states. Med Care. 1997;35(11):1095-108.

41. Ogdie A, Haynes K, Troxel AB, et al. Risk of mortality in patients with Psoriatic arthritis, rheumatoid arthritis and psoriasis: a longitudinal cohort study. Ann Rheum Dis. 2014;73(1):149-53.

42. Briggs A, Claxton K, Sculpher M. Analysing and presenting simulation output from probabilistic models: decision modelling for health economic evaluation. Oxford: Oxford University Press; 2006.

43. Stoner KL, Harder H, Fallowfield LJ, et al. Intravenous versus subcutaneous drug administration. which do patients prefer? A systematic review. Patient. 2015;8(2):145-53.

44. Tsiantou V, Athanasakis K, Theodoropoulou F, et al. Patients' and health professionals' preferences regarding intravenous vs subcutaneous drug administration: a literature review. Value Health. 2015;18(7):A742.

45. McInnes I, Nash P, Mease P, et al. Secukinumab for the treatment of Psoriatic arthritis: comparative effectiveness results versus adalimumab up to 48 weeks using a matching-adjusted indirect comparison. Clin Exp Rheumatol. 2016;34(4):782.

46. Nash P, Mclnnes I, Mease P, et al. Secukinumab for Psoriatic arthritis: Comparative effectiveness results versus etanercept up to 24 weeks using a matching-adjusted indirect comparison. In: 8th APLAR Congress, 2016. APL16-0827.

47. Strand V, Mease P, Mclnnes I, et al. Secukinumab for the treatment of Psoriatic Arthritis: comparative effectiveness versus infliximab using a matching-adjusted indirect comparison. Arthritis Rheumatol. 2016;68(suppl 10).

48. Soini EJ, Leussu M, Hallinen T. Administration costs of intravenous biologic drugs for rheumatoid arthritis. Springerplus. 2013;2:531.

49. Kobelt $G$, Jonsson $L$, Young $A$, et al. The cost-effectiveness of infliximab (Remicade) in the treatment of rheumatoid arthritis in Sweden and the United Kingdom based on the ATTRACT study. Rheumatology (Oxford). 2003;42(2):326-35.

50. (DoH) DoH. Reference costs 2007-08. London:DoH: 2009.

51. Hartman M, Prins M, Swinkels OQ, et al. Cost-effectiveness analysis of a psoriasis care instruction programme with dithranol compared with UVB phototherapy and inpatient dithranol treatment. Br J Dermatol. 2002;147(3):538-44.

Ready to submit your research? Choose BMC and benefit from

- fast, convenient online submission

- thorough peer review by experienced researchers in your field

- rapid publication on acceptance

- support for research data, including large and complex data types

- gold Open Access which fosters wider collaboration and increased citations

- maximum visibility for your research: over $100 \mathrm{M}$ website views per year

At BMC, research is always in progress.

Learn more biomedcentral.com/submissions 